\title{
¿QUÉ, POR FIN, ES EL SIGNO PEIRCEANO?
}

\author{
Floyd Merrell
}

Purdue University

\section{UNO, DOS, TRES, ... INFINIDAD}

Sigue un compás sincopado, esa esfera de la semiosis, que da origen al orden desde el caos. Sí, un compás sincopado: Uno, dos ... y tres - pausa ... y uno, dos ... y tres- pausa. Y sigue, en algún lugar y algún tiempo, nadie sabe precisamente ni dónde ni cuándo. La síncopa es la triadicidad peirceana en su expresión más genuina, a través de las roturas de la simetría que dan luz a la asimetría radical, a veces hasta el punto en que el caos amanece de nuevo.

El signo semiótico de Charles S. Peirce queda a este respecto lejos del binarismo semiológico y estructuralista. El signo semiótico es nolineal, en sentido sincopado. De hecho, se puede decir que es sincopado en sentido rizómico (Deleuze y Guattari, 1987). Es rizómico a la manera más radical imaginable. Entonces surgen las preguntas: ¿Abraza el signo triádico a todo?, y si no, ¿hasta qué punto se puede decir que ahí está algo que no queda incluido dentro de la esfera de la 
semiosis? $\mathrm{O}$, por expresar la cuestión de una manera aún más radical, Si el signo triádico abraza todo en simultaneidad, ¿no se puede decir, desde el otro lado de la moneda, que a fin de cuentas no abraza nada? es decir ¿puede que no haya nada que esté fuera del signo para que la abrace? Al ser así, parece que tenemos que resignarnos a nuestra existencia como agentes semióticos sumamente falibles, finitos e ignorantes-ignorantes, porque nuestra ignorancia está destinada a extenderse hasta el infinito, en comparación con nuestro pobrísimo conocimiento.

No,... dispénseme,... no es verdad eso. Debería haber escrito que ya que el signo goza de un compás como el de la síncopa, cuando menos podemos cultivar una «sensación» apropiada de él, podemos «sentirlo», aunque no se preste ni a ninguna descripción ni a ninguna explicación explícitas. Pero aunque no podamos saber en sentido discursivo precisamente lo que es, en el sentido más profundo, sí podemos conocerlo en un sentido visceral, corporal, de acuerdo con nuestras prácticas cotidianas. Entonces, tal vez podamos sentir el mero ritmo del signo, de signos, de todos los signos,... y tal vez no. Pero si no, ¿cómo podría ser yo capaz de articular esa bola de prácticas inefables e infinitamente vagas? Quizás de la siguiente manera ${ }^{1}$.

\section{HACIA UNA DEFINICIÓN DEL SIGNO}

El signo peirceano consta de un representamen, que es algo (en la mente o «allá afuera») que entra en relación con otra cosa, el «objeto semiótico», por una parte, y de un interpretante mediador, por otra parte, de tal manera que «trae el interpretante en relación con el objeto, lo que corresponde a la propia relación del representamen con el mismo objeto» (Peirce, 1931-35: 8.322). El representamen desempeña el papel de la categoría peirceana de la Primeridad, el objeto semiótico de la Segundidad, y el interpretante de la Terceridad. Pero esas relaciones no son tan simples como quisiéramos. Además, existe la Primeridad, la Segundidad y la Terceridad del representamen, del objeto y del interpretante. Así es que hay nueve niveles básicos de sig-

1 Desarrollo con más detalle la siguiente explicación del signo peirceano en Merrell (1995a, 1995b, 1996). 
nos. Correspondiendo a la Primeridad del signo, tenemos qualisignos, sinsignos y legisignos; a la Segundidad tenemos iconos, índices y símbolos; y a la Terceridad tenemos términos, proposiciones (o enunciaciones), y argumentos (o textos, discursos, narrativas). Pero de seguro esa profusión de términos amenaza meternos en un laberinto abrumador. Y de hecho, es un verdadero laberinto: las categorías corresponden a un trío que provee la posibilidad para todas las interrelaciones de los signos peirceanos, trío que puede ser cualificado de la siguiente manera:

(1) Primeridad: el modo de significación de lo que es tal como es, sin que haya referencia a, o relación con, ninguna otra cosa (una cualidad, sensación, sentimiento, o en otras palabras, la mera posibilidad de algún estado de conciencia de algo).

(2) Segundidad: el modo de significación de lo que es tal como es, y en relación con algo más, pero sin relación con ninguna otra cosa (eso es, la conciencia de algo que es otra cosa y aparte de esa conciencia).

(3) Terceridad: el modo de significación de lo que es tal como es, a medida que sea capaz de traer algo de la categoría de Segundidad en relación con algo de la categoría de Primeridad (por medio de una mediación entre las categorías de Primeridad y Segundidad).

En forma esquemática, la Primeridad es cualidad, la Segundidad es efecto, y la Terceridad es producto; así como la Primeridad es posibilidad (lo que pudiera ser), la Segundidad es actualidad (lo que es) y la Terceridad es potentialidad, probabilidad, o necesidad (lo que sería, podría ser, o debería ser, dadas ciertas condiciones prevalentes). No obstante, como todas las formulaciones esquemáticas, ésta, hay que conceder, es un poco ilusoria. En realidad, la Primeridad, de por sí, no es una cualidad de algo identificado e identificable (como lo es, por ejemplo, la sensación de una manzana que estuviera al alcance de nuestra vista en este momento). No es más que la pura posibilidad, una abstracción —es decir, ab-stracción, algo aislado de todo lo demáscomo algo que goza de la presencia de su propia autonomía, y nada más: no puede (todavía) presentarse $a$ la conciencia de algún agente semiótico sin abandonar su estado de Primeridad pura. Es una entidad sin partes definidas y definibles, sin antecedentes ni subsiguientes. Simplemente es lo que es, sin causas y sin consecuencias.

Lo que podría llamarse eso-aquí-ahora que existe para y dentro de la conciencia de algún agente semiótico pertenece a la Segundidad. Es cuestión de algo actualizado a la manera de esa entidad aquí-ahora y 
para alguien. Como tal, es una singularidad, una particularidad. Es lo que el agente semiótico tuvo delante de sí mismo como Primeridad, como por ejemplo una mancha roja sumamente vaga sin que haya (todavía) alguna conciencia de esa mancha o su identificación como tal y tal cosa. Pero ahora, como manifestación de Segundidad, esa mancha roja existe aparte del agente consciente, quien está dispuesto a verla como algo, sea ese algo una «mancha roja» que quizás pueda ser una «manzana». Pero a este nivel no lleva (todavía) un nombre como «manzana», es decir, no es todavía la palabra-signo «manzana» que identifica el objecto en cuestión y que lo relaciona con una masa grande de presuposiciones culturales respecto a la palabra «manzana» (la clase de manzanas a que pertenece esta manzana en particular, los múltiples usos de las manzanas y de la palabra «manzana», el papel de las manzanas en el folklore, los mitos y los cuentos de hadas, etcétera). En el primer grado de la Segundidad, la manzana es poco más que la posibilidad de una entidad física, un «hecho bruto», como Peirce mismo decía. Es sencillamente una cosa más entre la cuasi-infinidad de objetos que componen el mundo particular del agente semiótico: es la otredad en el sentido más primitivo. Si la Primeridad es la sensación pura de lo que es tal como es, la Segundidad es la negación pura en la manera en que es la otredad en juxtaposición a la Primeridad.

La Terceridad, dando testimonio de la influencia de Kant y Hegel sobre Peirce, parece un producto de la dialéctica. De esta manera la podemos cualificar tentativamente como lo que evoca la mediación entre las primeras dos categorías de tal manera que estén relacionadas la una con la otra del mismo modo en que están relacionadas con la Terceridad y la Terceridad con ellas. El acto mediario es como las esferas de Primeridad, Segundidad y Terceridad unidas y fundidas en un enredado nudo. De hecho, es como una variación del «nudo borromeano», que las liga por medio de un «eje» central de manera que están unidas alrededor del «eje» y de una manera «democrática» (Figura 1). Cada una de las categorías puede intermitentemente desempeñar el papel de cualquiera de las otras categorías. Sin embargo, en un «punto» espacio-temporal dado, una de las tres categorías estará considerada como Primeridad, otra como Segundidad, y otra como Terceridad. Para que ese proceso «democrático» tenga lugar, (co-)relaciones entre los tres «puntos» de la periferia de la Figura 1 pueden existir sólo por medio del «eje» central, el «cuarto punto». Si se quiere, se puede concebir al «eje» como el «punto unificador» que mantiene unidos los «rayos» de la «rueda» semiósica. La «rueda» está en movimiento perpetuo; en cambio, el «eje» permanece fijo: contiene la 


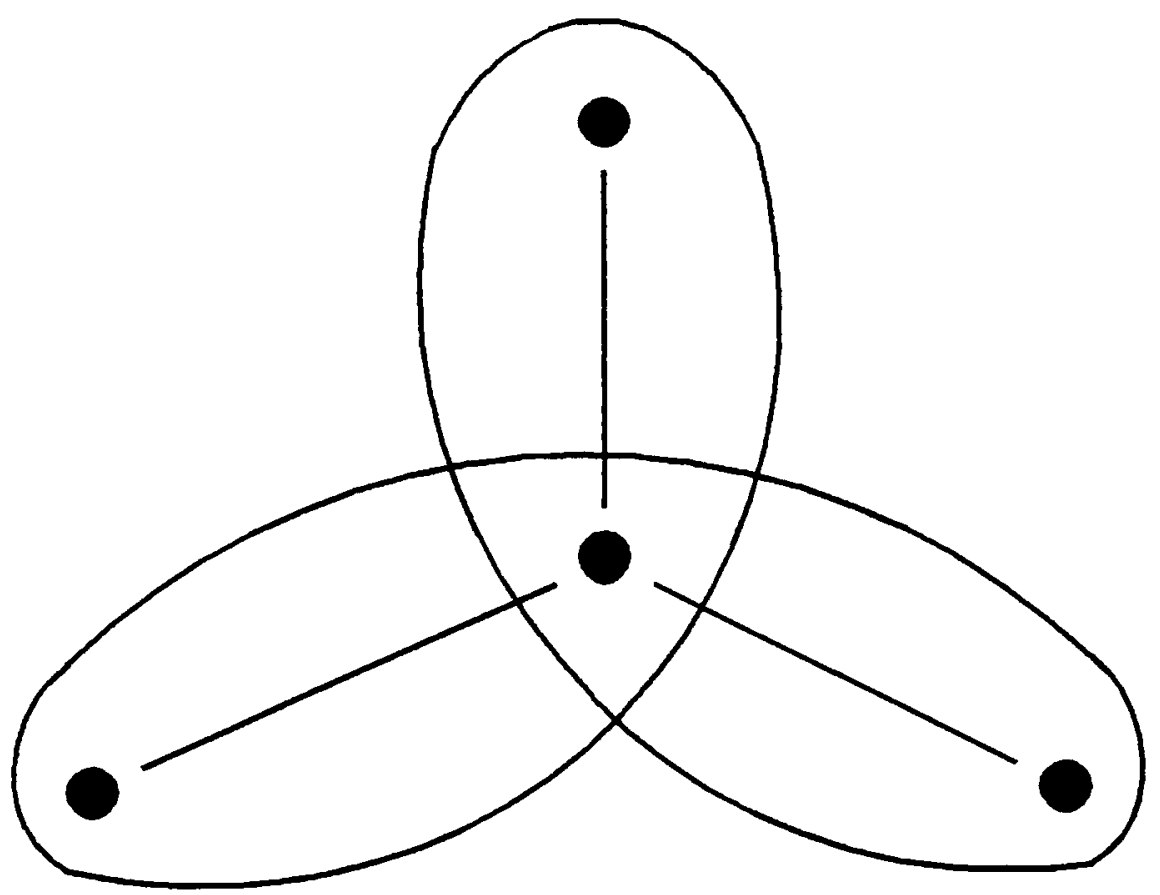

Figura 1

«grasa» que provee la continuidad del movimiento respecto a la «rueda» en su totalidad.

Ya que los «puntos» de la periferia de la Figura 1 pueden ocupar cualquiera de las tres categorías, lo que en algún «punto» espaciotemporal sea de Primeridad, consistirá en una sensación vaga. Lo que sea de Segundidad, abarcará apenas la conciencia de esa Primeridad de parte de algún agente semiótico. Y lo que sea de Terceridad, servirá para unir las otras categorías y darles algún significado como una entidad semiótica genuina. Es decir, si la Segundidad abarca el devenir de la conciencia al nivel en que el agente semiótico esté percibiendo una mancha «roja» (Primeridad) como «una manzana» (Segundidad), la Terceridad abarca el devenir de la conciencia hasta el grado en que pueda decir que «esta» entidad física «manzana» es un ejemplar de la clase de entidades que tiene como nombre «manzanas». La conciencia percibe que la «manzana», como todas las «manzanas», tiene cierta función en la vida cotidiana de la comunidad a la cual uno es ciudadano, dadas los atributos de una «manzana» que la cualifican como «manzana». Por lo tanto, la Terceridad tiene que ver con un signo como generalidad - las actualizaciones particulares del 
signo son de Segundidad-, según lo que Peirce denominaba convención, como resultado de la tendencia general de todos los seres vivientes de formar hábitos. De acuerto con los hábitos dentro de las convenciones de una comunidad, cierto conjunto de objetos semióticos estarán unidos dentro de una red interrelacionada de clases generales, de modo que el mundo físico bruto tome algún aspecto semiótico en general dentro del comportamiento y las interacciones humanas de esa comunidad. Dicho de otro modo, la palabra «manzana» ha llegado a ser una parte del habla acostumbrada, tácita, arraigada, y hasta automatizada. Tendemos a internalizar y externalizar nuestros signos dentro del vaivén de nuestras actividades cotidianas tal como los internalizamos y los externalizamos, sin hacer mucho caso al ritmo de esas actividades. Porque es, sencillamente, nuestra manera de semiotizar, y ya. Así es nuestro mundo al nivel de nuestra percepción y concepción tácitas.

Vemos, entonces, que la interacción del signo, el «objeto semiótico», y el interpretante no tiene que ver con la mera «substitución» de un objeto por un signo, de un signo que queda «en el lugar de» un objeto, de un signo que «se refiere a» un objeto, o un signo que «representa» un objeto. No. Todas estas concepciones implican relaciones binarias, no triádicas. La semiótica consiste en relaciones e interrelaciones, acciones e interacciones. No hay ni «representación» ni «referencia» en el sentido clásico; es decir, los signos no son «substitutos» de algo que en realidad no son. Al contrario, todos los componentes del signo dependen de, y colaboran con, los otros componentes del mismo signo y con todos los componentes de todos los signos dentro del río profundo de la semiosis. Todos los signos fluyen.

\section{ENTONCES, ¿CUÁL ES EL PROBLEMA?}

Desafortunadamente, uno de los errores más grandes de las exposiciones y las aplicaciones de la semiótica peirceana queda en la obstinación por presentar las relaciones triádicas como si fueran un trío de relaciones binarias. Ese problema posiblemente sea en parte por la tendencia, el hábito, de construir imágenes euclideanas. Por lo tanto cuando pensamos en términos de tres, a pesar de nuestras buenas intenciones, automaticamente un triángulo aparece en la mente. 
La «geometría» de nuestra vida cotidiana, nuestra habla y nuestros pensamientos, es invariablemente euclideana. Es decir, el pensamiento euclideano es nuestro por inculcación. Se nos fue implantado en el cerebro como un retrato del mundo tal como es o cuando menos tal como debe ser, sin «porqué» ni «para qué»: se suponía y se supone que así son las cosas, y ya. Después de generación tras generación de inculcamiento de la cosmovisión cartesiana-euclideana-newtoniana, ahora es casi imposible concebir el mundo de otro modo: no hay mundos alternativos, porque al haberlos, serían considerados como mundos de la pura imaginación, la alucinación, o el sueño. Es decir, somos el producto de más de 2.000 años de indoctrinación, con todos los prejuicios y las preconcepciones, de una expansión de lo que fue en el comienzo la metafísica griega.

Pero desde hace varias décadas algunos psicólogos nos han dicho, sobre todo después de las investigaciónes de Jean Piaget (1973), que los niños no son simplemente «pequeños salvajes euclideanos» con cerebros que funcionan igual que computadoras digitales (en particular, Gardner, 1987). La perspectiva del mundo de los niños antes de tener pleno dominio de una lengua puede clasificarse de modo no-lineal y háptico (Yourgrau, 1966). La experiencia háptica incluye, aparte de lo visual y lo auditivo, un sentido de lo que es tacto, sabor y olor. Y contrasta con los hábitos ya fijos de los adultos acerca del habla, de líneas trazadas en una hoja en forma de escritura, de visión binocular, del sentido de profundidad de una imagen de dos dimensiones en la televisión y el cine, y del ritmo en la música y la danza. Leemos en los historiadores y los antropólogos que otras culturas no necesariamente han seguido el camino real de las líneas convergentes euclideanas y las esferas pitagóricas, tan esenciales a nuestro modo de percebir y concebir al mundo. Las culturas tradicionales suelen practicar lo que llama Claude Lévi-Strauss (1966) la «ciencia de lo concreto»-que consiste del mundo de los fenómenos vistos como una red compleja de clases y categorías- en lugar de nuestro mundo de la «ciencia de lo abstracto» - siguiendo el ideal de la matematización del universo. Sin embargo, los dichos «primitivos» no son sencillamente «como niños» en cuanto a su percepción, concepción, y articulación, mientras nosotros existimos imperiosamente arriba y más allá de ellos, con la mente apropriadamente iluminada. Por lo que toca a la idea que ellos tienen de los misioneros cristianos, los antropólogos y los turistas, somos precisamente nosotros los que a ellos les parece que nos comportamos «como niños». $\mathrm{Y}$ en eso tienen bastante razón (Tyler, 1987). 
Al comienzo del presente siglo y a fines del siglo pasado, pensadores revolucionarios como Friedrich Nietzsche, Gottlob Frege, Sigmund Freud, Edmund Husserl y Bertrand Russell permanecieron enmarañados dentro de los principios clásicos de la lógica, las líneas euclideanas, los coordinados cartesianos y las leyes de la causalidad. Nietzsche estaba obsesionado con el eterno retorno, el cual fue una parte de la mecánica clásica newtoniana e incompatible con la ciencia de nuestro siglo y, cabe decir, que, investigadores como Peirce ya estaban al tanto de la limitación de ese concepto. Freud - sobre todo durante los primeros años de su carrera- fue en cierto sentido un tipo de «romántico mecanicista». Husserl mantenía su fe en que tenemos la capacidad de hacer a un lado todo lo que no es necesario a nuestra percepción del mundo para ver las cosas como deben ser vistas. Y Frege y Russell, durante las primeras décadas de este siglo, creían que el edificio entero de la matemática podría ser reducido a un conjunto simple de axiomas lógicos. Hasta el mismo Albert Einstein no podía desechar su insistencia de que Dios no «juega dados» con el universo, y se mantenía firme en la búsqueda de una teoría totalizante capaz de dar cuenta de todo el universo, ayer, hoy y siempre. Y para colmo, tenemos la imagen de Ferdinand de Saussure del lenguaje como un juego de ajedrez, la lengua según una imagen digital, diádica, estática en un momento dado, y abierta a la vista del lingüista desde una perspectiva sub specie aeternitatis. Pero ya basta de digresiones. Al grano, con el concepto peirceano de los signos en proceso.

\section{TODO ES PROCESO}

Es, desde luego, difícil expresar la idea de proceso respecto a la lengua, porque una lengua por naturaleza divide el mundo en objetos, actos y acontecimientos discretos. No sorprende, a este respecto, que el signo triádico de Peirce sea generalmente diagramado en forma de triángulo (por ejemplo: Ogden y Richards, 1923). La Figura 2 es una forma acostumbrada y fácilmente reconocible. Cualquier alumno de la escuela primaria puede identificarse con ella, y coincide con nuestra tendencia de euclideanizar el mundo.

Pero no es genuinamente triádica. No consiste en más que un conjunto de tres relaciones binarias: representamen-objeto $(R-O)$, representamen-interpretante $(R-I)$, y objeto-interpretante $(O-I)$, ni más, ni 


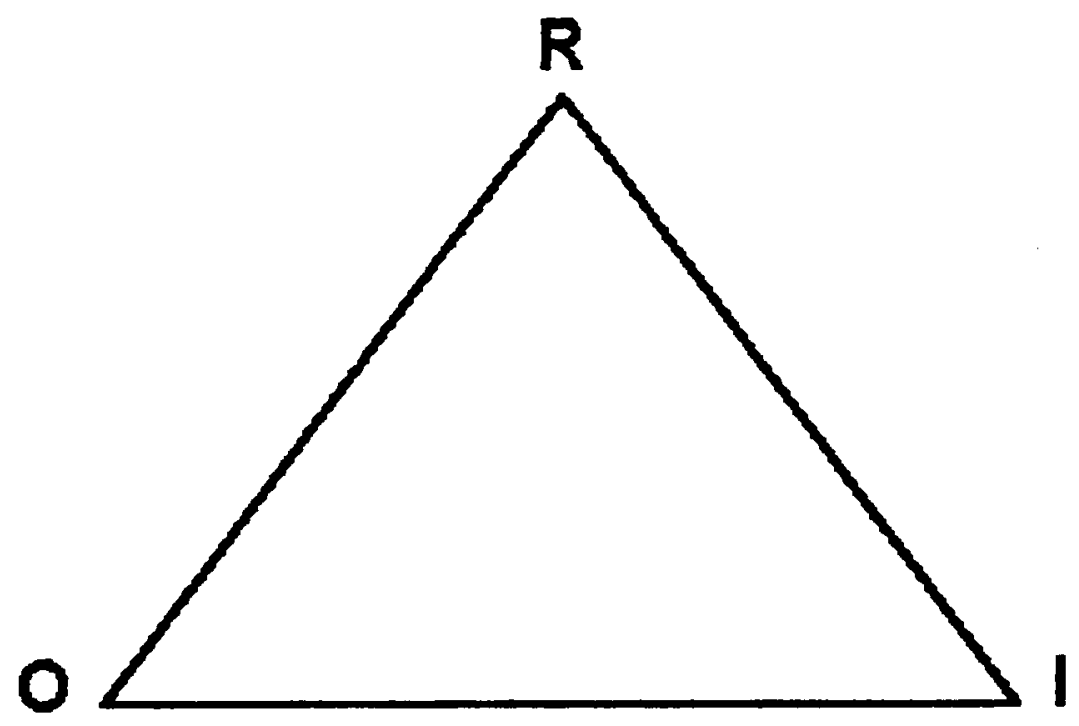

Figura 2

menos. No hay triadicidad genuina. En cambio, la Figura 3 (engendrada de la Figura 1) liga cada componente del signo con los otros dos componentes, y además, los liga a la relación entre ellos. La relación entre $R$ y $O$, por ejemplo, no es ninguna relación fuera de una consideración de las relaciones entre $R$ e $I$ y entre $O$ e $I$. Y ninguna de las

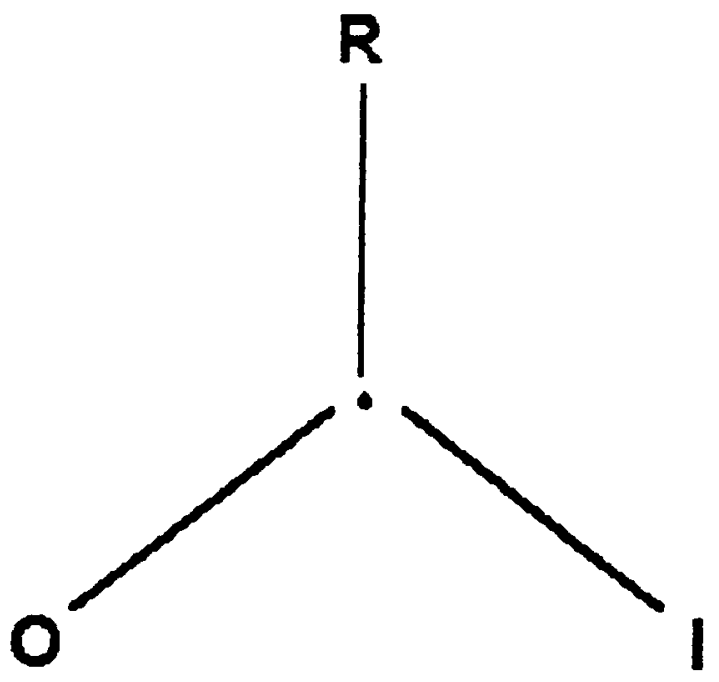

Figura 3 
relaciones son válidas fuera del «eje», la «nada» por decirlo así y como Peirce mismo lo decía, conectando todos los componentes semióticos (Peirce, 1931-35: 4.12).

Compárese la Figura 3 al concepto peirceano del signo tal como está desarrollado arriba: deje que los ojos vaguen de un componente del signo al «eje» a medida que recapitule usted la definición verbal del signo; después, siga el camino a otra faceta del signo, y luego al «eje» y al tercer componente semiótico. Y siéntase la fluidez del movimento triádico de la semiosis. ¿Ya lo sintió? «Pero ese "eje", ¿es en realidad necesario, o es sólo una complicación suplementaria del signo?», replica algún escéptico. Bueno. Me supongo que lo único que puedo hacer en términos de una respuesta, ya que el tema implica una problemática algo compleja, es a través de una sugerencia sumamente vaga: el «eje» es, para repetir la fórmula, de la naturaleza del «vacío» budista, o de la «nada» de Peirce, como se ha mencionado arriba. Es la «nada» («nothing», «no-thing), sin embargo implica la posibilidad de «todo» («everything», «every-thing»). Es la puerta por la cual pasan todos los componentes de los signos durante su interacción con los otros dos componentes y con todos los signos de la cascada semiósica. Es un tipo de «pre-Primeridad», el «vacío», que mantiene todo dentro de su abrazo íntimo, como la posibilidad de todo lo que ha sido, es y será actualizado, aunque dentro de esa posibilidad pura no hay nada actualizado —otra vez Peirce emplea esos términos en un sentido cercano a la filosofía budista (véase Baer, 1988) - . Es, por decirlo así, un conjunto de posibilidades que dan luz a la fuente de la creatividad semiósica, que nunca puede estar en paz sino que es el repositorio de un devenir incesante de signos.

Si usted quiere una imagen de ese proceso semiósico, mire la Figura 4. Ofrece una ejemplificación más concreta de la relación entre el signo peirceano y sus componentes. En este caso, el signo inicial $\left(R_{1}\right)$ puede consistir de un nombre, por ejemplo, «Joe», que puede ser una manifestación o de ciertas ondas en el aire o de algunas marcas negras en una hoja blanca. Pero a las preguntas «¿qué Joe?», «¿dónde?», «¿cuándo?», «¿qué es lo que tiene Joe?», etc., no existe (todavía) ninguna especificación (es decir, no hay ni un $O_{1}$ ni un $I_{1}$ genuino). El signo permanece demasiado vago, aunque puede ser un signo como un tipo o una generalidad de la manera más general imaginable, ya que el nombre puede entrar en relación con todos los «Joe» del universo, pasados, presentes y futuros. El siguiente grado en la determinación del signo «Joe» entra con su uso como una particularidad o «token» 


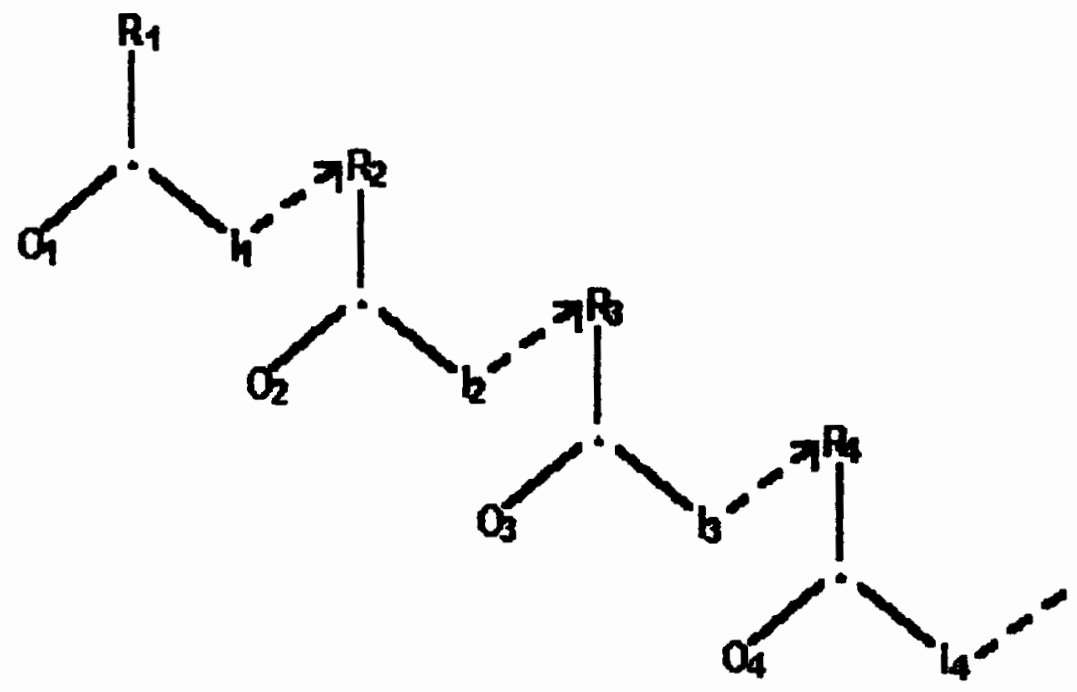

Figura 4

con respecto a una persona en específico. Entonces cumpliré con este requisito al aludirme a «Joe» como «Joe Camello» (del anuncio de los cigarros «Camel»).

Ahora bien, el «Joe Camello» $\left(R_{2}\right)$ en que estoy pensando es una réplica de más o menos 70 metros de altura, pintada en el costado de un edificio, el cual no tiene ventanas y es de cemento, que se encuentra en la Avenida Paulista y la Calle Consolación en San Pablo, Brasil. «Joe» tiene pantalones de mezclilla («jeans»), una chaqueta negra de cuero, lentes oscuros, y, desde luego, el ubicuo cigarro «Camel» colgado del labio de la parte derecha de su boca. Está sentado en una motocicleta con la rueda delantera torcida un poco a la izquiera de tal manera que da énfasis al cigarro. Su mano derecha está colgada del manubrio derecho de la motocicleta. Esa mano tiene tres dedos (en lugar de cuatro), que están en línea paralela con su hocico y su boca. El farol de la motocicleta apunta hacia abajo, en dirección al espectador: una columna imaginaria de luz arrojada al sujeto, que complementa la columna enorme del cigarro blanco en la boca del camello, que es, desde luego, el tema principal de toda la gigantesca imagen. En fin, todas las señales, motocicleta, mano, dedos, hocico, boca, sirven para destacar hasta más la presencia del cigarro.

Ah. Cabe decir que en el rincón del sureste de la imagen se encuentra la advertencia del Cirujano General - lo que es requisito respecto 
a tal publicidad - dando el informe de lo peligroso del producto. Pero, lo que parece cosa de la pura casualidad, el anuncio queda casi oculto detrás de unos árboles en frente del edificio. Más relevante aún, esos árboles proveen sombra para un pequeño jardin de niños, con calumpios, resbaladillas, arena para jugar, y diversos juegos. Contemplado desde el sitio donde juegan los niños, «Joe» ofrece un panorama impresionante, $\mathrm{y}$ hasta arrollador.

Hasta ahora he vestido un sólo signo, «Joe», con una complejidad de signos en interrelación que pueden ser interpretados de diversas maneras. La moraleja de mi pequeña historia es que la Figura 3, aparentemente un simple «eje» con tres líneas equidistantes y cada una con un «punto» en el extremo, presenta lo que podría ser concebido como una imagen algo estática: no hay indicación necesaria de movimiento, dinámica, proceso, fluidez. Para que exista la creación de una imagen genuina de la semiosis, debe existir la posibilidad de que el $I$ (interpretante) pueda llegar a ser otro $R$ (representamen) que relaciona a su respectivo $O$ (objeto semiótico) - que es ahora otra cosa de lo que fuey todo, como signo, a su vez engendra otro $I$, que ya está en el proceso de engendrar otro $R$, y así sucesivamente. Según ese proceso, y en vista de la Figura 3, obsérvese la Figura 4. Un signo o representamen $\left(R_{1}\right.$, «Joe $\left.{ }_{1} »\right)$ se vuelve en (se «traduce en») su signo como sucesor $\left(R_{2}\right.$, «Joe ${ }_{2}$ » como un camello rebelde, lo que atrae a los niños y la juventud) por medio de $R_{1}$. E inmediatamente $R_{2}$ llega a ser (se «traduce en») el próximo signo $\left(R_{3}\right.$, «Joe 3 » como significado de los cigarros «Camel»), con su respectivo $O$ e $I$, y mientras gira alrededor del «eje» central en algún vértice en el hirviente río semiósico. De esta manera, cada instancia del «mismo» signo (una réplica) engendra un signo que es ahora un signo diferente, aunque esa diferencia sea infinitesimal: la semiosis nunca puede ser estática; es un fluir efervescente. Solamente de esta forma pueden todas las relaciones del río semiósico componer una totalidad auto-organizante - un rizoma interconectado con un sinnúmero de «ejes» cada uno de los cuales es un centro, su propio centro, y la circunferencia de la cual no está en ningún lugar determinable-.

\section{V. ¿PUEDE SER UN SIGNO UNA ISLA SOLA?}

Relacionando ese proceso entero con el concepto del signo como una «transformación» o «traducción» de otro signo, supóngase que usted no 
sabe el significado de la palabra «world», y, búscandola en un diccionario Español-Inglés, encuentra «world», que corresponde a «mundo».

Ahora sabe que lo que significa «mundo» para usted, «world» significa más o menos el equivalente. Es decir, la palabra «mundo» puede significar algo diferente para cada hispanoparlante, aunque todos comparten alguna idea o concepto de lo que es el significado de «mundo», y el significado de «mundo» es más o menos igual al significado de «world», aunque entre todos los angloparlantes existen pequeñas diferencias en cuanto al significado de la palabra «world». Pero a pesar de todas esas diferencias, usted sabe ahora usar la palabra «world» con bastante eficacia como para comunicarse con otros hispanoparlantes que saben inglés y con los individuos que componen la comunidad de angloparlantes. En otros términos, usted ahora sabe que: (1) «mundo» es un signo mediador y relacionado con «world» como un signo de básicamente el mismo «objeto semiótico» que significa el signo mediador, «mundo» y (2) world es ese objeto en el espacio sobre el cual existimos, que para decir «world» es más o menos igual como para decir «mundo» y por lo tanto «mundo» es el interpretante para «world». Las dos palabras como términos generales no denotan nada más que cierta forma que pertenece a sí mismo y sólamente a sí mismo (véase Savan, 1987-88).

No es que simplemente estoy ignorando la idea de la «referencia», o más bien, las relaciones entre los signos y las cosas. No. Estoy haciendo hincapié en la función de la «traducción» como más bien una cuestión de relaciones entre signos y signos y entre signos y cosas. Esas relaciones entre signos, en el sentido de la «traducción», incluyen relaciones entre signos y cosas como un «subconjunto». Entonces tenemos signos (representamenes), objetos («objetos semióticos») y sentido y significado (en su unión, interpretantes). De esta manera podemos decir que (a) «"World", "monde" y "Welt", tienen la mayoría, pero no todos, los atributos que tiene "mundo" en su relación con ese cuerpo esférico que gira alrededor del sol sobre la superficie del cual existimos, aquellos atributos que son semejantes y hasta se parecen, aunque no son absolutamente idénticos». $O$, desde un punto de vista complementario, podríamos decir que (b) «"Mundo" es esférico y «world» es esférico y "monde" es esférico y "Welt" es esférico». En otras palabras, (a) evoca los atributos de los signos en relación a otros signos y a sus respectivos objetos. Además, al hacer esas relaciones, aludimos a lo que Peirce denomina su profundidad (depth) de algún signo. De esta manera, la imagen de la profundidad entera de un signo 
contendría una enumeración de todos sus atributos. Decir, «El "mundo" es una esfera un poco imperfecta y gira alrededor del sol de manera elíptica y queda entre Marte y Venus y es habitable y su capa de ozono escasea, etc.», da al signo en cuestión creciente profundidad. Sin embargo, con respecto a la «traducción», que abarca la predicación (b), una mera lista de los atributos del signo le otorgaría poca extensión («breadth»). La extensión de un signo incluye una serie de ejemplificaciones (particularidades o «tokens») de él, de manera que su generalidad (como tipo, o la clase de cosas a la cual pertenece) en relación a su objeto quede cada vez más especificado. Le extensión completa de un signo, entonces, consistiría en la totalidad de sus posibles ejemplificaciones o actualizaciones, incluso todas las relaciones a todos los objetos posibles en el mundo físico y todos los interpretantes posibles. La proposición (b), por lo tanto, da cuenta de la aplicación de un signo, pero no de la profundidad de un signo, de su repertorio de atributos.

No obstante, no hay que menospreciar la extensión de los signos. Los signos pueden cobrarse de más extensión a través de su uso dentro de diversos contextos en diversos lugares. Eso sirve para dar más riqueza a los signos. Por ejemplo, "Mundo" para un campesino brasileño no incluye el conjunto global de naciones, culturas, y pueblos, mientras para un profesionista de la clase media de Argentina el mismo signo se carga de un significado más expansivo». Conciencia de estas dos aplicaciones posibles de la palabra del mismo signo de parte de un campesino brasileño o un argentino citadino es esencial para una comprensión cabal de su profundidad. También implica el uso del signo y la conciencia de la extensión como una generalidad (o tipo) que es más o menos aplicable a ciertas clases de circunstancias. En este sentido, una conciencia apropriada de la extensión de un signo exige una conciencia complementaria de su profundidad: la extensión sin profundidad no puede enriquecer el significado de un signo; la profundidad sin extensión no es capaz de aplicar cabalmente el significado de un signo a otros signos.

Entonces si extrapolamos nuestro diagrama con respecto al concepto del signo «traducción», tendremos una variación de la Figura 4 , donde $R_{1}$ sería «mundo», $R_{2}$ sería «world», $R_{3}$ sería «monde», $R_{4}$ sería «Welt», etc. La diferencia es que ahora estamos considerando la «traducción» en el sentido convencional, mientras que en el caso anterior la idea de «traducción» abarcaba re-iteraciones de lo que podría haber sido considerado como el mismo signo pero en diferentes sitios y en 
diferentes momentos. No obstante, como el mismo signo sufre alteraciones incesantes desde un «punto» espacio-temporal a otro, de la misma forma el signo en una lengua sufre cambios en el pasaje a otras lenguas, aunque se supone que el «mismo» signo en diferentes lenguas esté relacionado con el «mismo» objeto. Ya que dentro de diferentes lenguas los signos y sus respectivos objetos son más o menos los «mismos», así también los interpretantes de esos signos son diferentes.

«Y, ¿qué pasó con "Joe"?» pregunta alguien. Ah, sí, «Joe». Un signo bastante sencillo, ¿no? Pero al pensarlo un poco, nos damos cuenta de que de ninguna manera es sencillo. De hecho, como todos los signos peirceanos, «Joe» tiene la potencialidad de ser infinitamente complejo en cuanto a todas sus interpretaciones posibles. Pues, de seguro, «Joe» es el «mismo signo» (o simulacro), como una particularidad (token) que consiste de un temblorcito de ondas en el aire o algunas rayas en un pedacito de papel o en la computadora. Pero dentro del contexto de la semiosis humana, y dado el número potencialmente infinito de «puntos» espacio-temporales y su uso casi sin límite en cuanto a los valores culturales y las convenciones sociales, tiene que ser un signo diferente con cada una de sus instancias. Muchos de sus usos pueden diferirse tanto como «mundo» para un campesino peruano o un hombre de negocios de Buenos Aires y «world» para el habitante «yuppie» de la Quinta Avenida de Nueva York. Pueden ser esencialmente de la índole de «traducciones». De la misma forma, «Joe» puede ser «Joe cool» para un niño de diez años en el jardín de la Avenida Paulista de San Pablo, Brasil, ya que quedó bastante impresionado con la imponente y omnisciente fugura de la cual no puede quitar la vista. Pues sí, «cool». En contraste, su vecino de catorce años, pandillero, rebelde y muy sábelotodo, quizás dijera del icono del camello: « $i$ "Joe"? No es nadie en especial. Ni me impresiona gran cosa ni me afecta». Y libremente ofrece su opinión con un cigarrillo prendido entre los dedos - desde luego, es un «Camel». Por cierto la mamá de ese pandillero guarda algunas palabrillas criticonas con respecto a «Joe». Cree que influye de manera maliciosa en las mentes inocentes, y por lo tanto deben prohibir toda la publicidad de ese tipo. Aquella noche en la seguridad de su despacho, un investigador algo presumido y pedante de la universidad escribe un artículo sobre «Joe» como ejemplo de la posmodernidad según la «lógica de la cultura del capitalismo tardío», con la esperanza de conquistar la fama que cree merecer dentro de los círculos académicos. Y las posibilidades de «traducción» del signo solitario, «Joe», siguen aumentándose cada vez más. 


\section{CORRIENTES Y VÉRTICES Y HURACANES Y CICLONES: LA SEMIOSIS}

La idea del cambio de significado o la «traducción» de los signos trae recuerdos del signo efervescente, templante, titubeante, chispeante, en rotación de las Figuras 1,3 y 4 . Un $I$ se vuelve en un $R$, que se interrelaciona con ("gira alrededor de») su propio $O$ e $I$, y el $O$ o el $I$ en el proceso se vuelve en otro $R$.

Se comparan esas «revoluciones» con una imagen encontrada en muchas formas en diferentes culturas, a veces con el nombre de «La Isla de las "Piernas que Corren"» (Figura 5). Es un signo antiguo con el fin de engendrar la idea del proceso: las tres piernas se persiguen las unas a las otras alrededor de un «eje» estático. El problema es que, una vez más, el pensamiento clásico invariablemente tiende a emerger y dominar la imagen. El trío de piernas podría caber dentro del concepto de un «grupo cíclico» de la «teoría de grupos», un tipo de la «simetría rotativa». El «álgebra» de tales rotaciones es bastante simple: gire usted una pierna $120^{\circ}$ y queda transformada («traducida») en la siguiente pierna, y entonces repita la operación, ad infinitum. En realidad, la rotación de las piernas de la tríada peirceana (Figura 3) queda casi, pero no absolutamente, igual. Es decir, son los autores de la «rotura de la simetría» más bien que la creación de la simetría. Cada

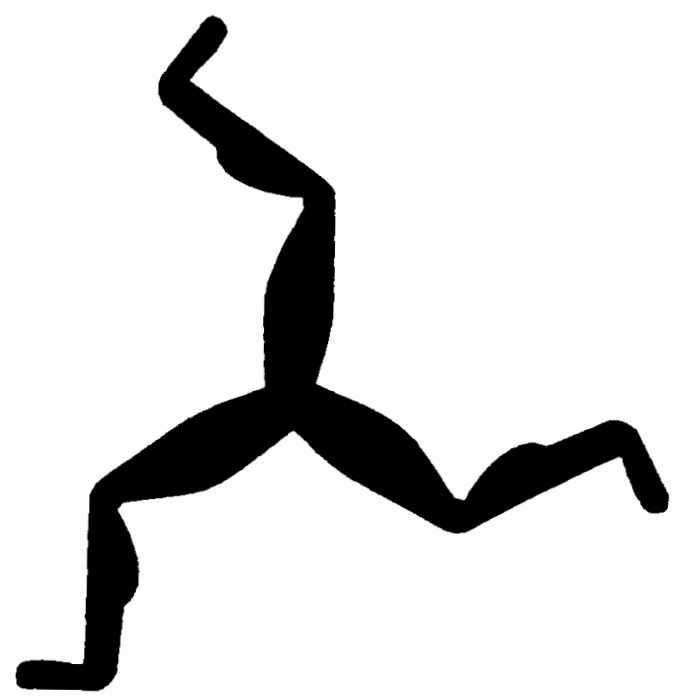

Figura 5 
«traducción» de un componente del signo no deja un arco en el plano cartesiano sino describe un espiraloide en el espacio tridimensional: después de cada ciclo no hemos vuelto al origen sino a otro lugar fuera del plano de acuerdo con una trayectoria no-simétrica. Es como el litógrafo de Mavrits Escher, «Ascendiendo y Descendiendo», que consiste en varios monjes subiendo unas escaleras que terminan donde comienzan. Vemos que los monjes no están progresando, pero desde su propio punto de vista están subiendo cada vez más hacia el cielo y más cerca de Dios. Y es, precisamente, su punto de vista lo que importa, ya que ellos, como todos nosotros, están envueltos en sentido inmanente dentro de la confluencia semiósica de su universo.

Ahora bien, si la simetría es la palabra clave, y si el concepto de rotación debe ser el foco de nuestra atención, la pregunta es: ¿Cuál es la dirección de la rotación y cómo es que causa la alteración del signo? «Pero», nuestro escéptico ubicuo interviene, «¿A fin de cuentas qué importa? A la derecha a la izquierda, ¿no?» Bueno, la diferencia tiene que ver con la «dextrorrotación» en contra de la «levorrotación», entre la simetría poderosa, una pequeña ruptura de la simetría, y una rebelde asimetría o antisimetría. La física clásica en realidad tiene poco que decir sobre ese tipo de fenómeno. Posición, dirección, izquierda, y derecha, todos son conceptos relativos. Casi no hay preferencia respecto a una cosa o la otra. La simetría absoluta, de forma semejante, no tiene preferencia respecto a las direcciones. Una esfera perfecta es puramente simétrica. Podemos girarla cuantas veces queramos, y queda igual: es la misma esfera y ocupa la misma cantidad de espacio.

En cambio, la simetría bilateral-como la relación entre un objeto y su imagen especular - es un poco menos que pura, y ha captado el interés de muchos investigadores. Kant estaba fascinado con la simetría bilateral, igual que Leibniz. Una imagen especular es igual y al mismo tiempo es diferente. Pónga su mano derecha enguantada delante del espejo, y se vuelve en la mano izquierda y el guante izquierdo. Si el guante es de hule para uso en la cirugía, la operación para convertir el guante izquiero al guante derecho es simple: voltearlo. Pero si el guante es grueso, la operación se vuelve casi imposible, y entonces puede llegar a ser el guante derecho sólo por convertirlo en una infinidad de puntos matemáticos y transformarlo a través de una infinidad de operaciones topológicas. Si Alicia, después de haberse acostumbrado a su País de las Maravillas, hubiera dado la vuelta para contemplar su mundo ordinario, habría descubierto que el mundo «real» que dejó 
ahora es un mundo extraño. Una de las primeras cosas que vió al entrar en su nuevo mundo fue un reloj. Los números estaban al revés y las manecillas daban vuelta en sentido contrario. Pero en realidad, la dirección no tiene relevancia; un reloj podría funcionar tan bien en sentido contrario como en sentido ordinario. Da igual. Otra relación complementaria de Lewis Carroll reside en los gemelos, Tweedledee y Tweedledum. Cuando saludaron a Alicia, uno extiende la mano derecha y el otro la mano izquierda. Si su simetría fuera genuina, entonces un gemelo sería dominado por el hemisferio cerebral derecho y el otro por el hemisferio izquierdo. Serían verdaderamente gemelos idénticos, pero en sentido bilateral.

Diseños y rotaciones en sentido contrario a la dirección de las manecillas de un reloj se encuentran a menudo en diversas culturas humanas. La mayoría de los tornillos dan vuelta de izquierda a derecha. Sin embargo, en los Estados Unidos, carros, caballos, perros y seres humanos corren de derecha a izquierda alrededor de la pista durante las carreras. De esta manera, los ojos se mueven de izquierda a derecha al observar el espectáculo en la pista que tiene uno delante, como si uno estuviera leyendo un libro. Para leer el hebreo y ciertas otras lenguas, en cambio, los ojos pasan de la derecha a la izquierda. Y en Inglaterra, donde los volantes de los carros están a la inversa de los carros de los Estados Unidos, las carreras van en la dirección de un reloj. Las mismas palabras, «izquierda» $\mathrm{y}$ «derecha», dan testimonio en muchas lenguas del prejuicio que la comunidad tiene en favor del lado derecho, tal vez porque tenemos la tendencia de usar la mano derecha -los «zurdos» cuentan entre más o menos $10 \%$ de la población en cualquier sociedad-. Siniestro proviene del latín, que quiere decir izquierdo, mientras diestro es un término que se usa para indicar la derecha. Gauche en Francés quiere decir «chueco» o «torpe», mientras droit indica «honrado» o «recto». En Alemán, link es izquierda, y linkisch es «torpe», mientras recht, o derecha, quiere decir «verdad» o «franco» o «sincero». La mayor parte de las distinciones, sin embargo, parecen arbitrarias, idiosincráticas y dependientes de una cultura dada más bien que biológicamente determinadas.

De más interés con respecto a la semiótica peirceana es el hecho de que la vida misma es un poco asimétrica. Louis Pasteur fue uno de los primeros científicos en fijarse en que las moléculas que componen los organismos vivientes vienen en formas «enantiomórficas», es decir, de simetría bilateral. A este respecto es interesante ver que el hélica asimétrica del DNA, un espiraloide asimétrico, casi invariablemente 
da vuelta de la izquierda a la derecha ${ }^{2}$. El cuerpo humano, y la vasta mayoría de todos los demás organismos, manifiestan una simetría bilateral. Pero en todos los casos la simetría no es perfecta sino que existen pequeñas variaciones. La simetría bilateral tiende a perseverar en el interior del cuerpo, pero en algunos casos la simetría queda radicalmente destruida, como por ejemplo en el corazón, el hígado, el apéndice y el páncreas. Ciertos órganos del cuerpo humano y de otros organismos manifiestan una enroscadura asimétrica - los caracoles, los cuernos de borregos, caballos del mar-. Esas torceduras generalmente favorecen una dirección u otra. Las conchas de los caracoles casi siempre tienen espiraloides hacia la derecha cuando son vistas desde arriba, por ejemplo. Sin embargo, pocos biólogos creen que ese fenómeno esté ligado al espiral molecular del DNA. Nuestro mundo podría haber sido completamente al revés, si hubiéramos nacido en el País de las Maravillas. Pero de todos modos, la vida seguiría igual, con las mismas tensiones y placeres, los mismos momentos de jubilación y de mortificación, los tiempos de guerra y de paz y de amor y de odio, como experimentamos en nuestro mundo, al cual nos hemos acostumbrado.

\section{VII. iAL GRANO, AL GRANO!}

«A fin de cuentas, ¿cuál es la tesis de usted?» Pues, la tesis es que las ideas de «verdad» y «falso» de la lógica clásica y del discurso del positivismo lógico son, a fin de cuentas, oposiciones binarias.

Desde luego, según las categorías de Peirce, tenemos la Primeridad, y su otro, la Segundidad, una cosa y otra cosa que la pri-

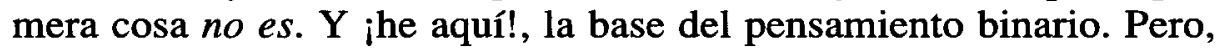
¿qué es de la Terceridad? Quizás quisiera uno concluir que la Terceridad es la mediación entre lo que es y lo que no es de modo que emerge a la luz del día la interpretación de una de las dos cosas como más adecuada que la otra. Pero no es así, en vista de lo susodicho. Además, si seguimos a los «nuevos filósofos de la ciencia» Thomas

2 Cabe decir que el físico Erwin Schrödinger en 1945 sugirió que en su manifestación más fundamental la vida consta de «cristales aperiódicos», lo que resultó en una premonición que fue comparada con el descubrimiento del DNA algunos años después (Schrödinger, 1967). 
Kuhn, Norwood Hanson, Michael Polanyi, y Paul Feyerabend, y si hacemos caso a los consejos de Ludwig Wittgenstein, Hilary Putnam y Nelson Goodman, tanto como a los de Peirce u otros pragmatistas tales como William James y John Dewey, y aun el «perspectivismo» de Friedrich Nietzsche y algunos de sus discípulos, Michel Foucault y Gilles Deleuze, y hasta Richard Rorty, no podemos menos que concluir que las «verdades» de ayer pueden ser las «falsedades» de hoy, y viceversa.

Lo que es y lo que no es necesita una dosis masiva de la Primeridad, o sea, del azar, la chance, la incertidumbre, y sobre todo, la vaguedad. Y la mediación a través de la Terceridad tiene que traer la noción de que por precisa que sea la concepción de un signo, de un conjunto de signos, de una teoría, o de la ejemplificación de la teoría, siempre existirá un elemento de indeterminismo, y por eso de la incompletitud. Así es que todo signo que aparezca casi inmediatamente se transforma en otro signo con otro significado. No hay, ni puede haber, ningún signo que quede tal como es por todos los siglos de los siglos. De esta manera, aunque «Joe Camel» esté bien enraizado en los anales de la publicidad como un signo general, como un tipo, capaz de engendrar un sin número de signos particulares (tokens), de todos modos nunca es el mismo «Joe Camel».

Entonces de nuevo tenemos: «uno-dos ... y entonces tres — pausa ... y ..». El compás sincopado, asimétrico, espiraloide, corre por la cascada semiósica. Lo que sí es cierto es que seguirá su danza. Y estamos nosotros dentro de la danza, querámoslo o no. ¿Y «Joe»? Pues, es sencillamente «Joe». Pero en realidad es una imagen bastante única. Hay que conceder que él no tiene la culpa de la influencia que tiene en sus interpretadores, porque no es más que un signo. Pero, después de todo lo dicho y hecho, sus interpretadores, todos nosotros, tampoco somos más que signos, entonces tampoco tenemos la culpa de nada, ni la tienen los agentes de la publicidad que crearon a «Joe». Pero espérese. No. Eso no es «verdad». Debo retraer lo que acabo de escribir. El hecho es que todos somos responsables, por grande o pequeño que haya sido nuestro papel en la procreación de los signos culturales y la manera en que se interpreta. Porque como signos, ejercemos alguna influencia sobre todos los signos en el proceso semiósico, sepámoslo o no.

Si recuerdo bien, Jean Paul Sartre escribió algo por el estilo con respecto a nuestra existencia. Pero, esa, desde luego, sería otra historia. 


\section{Referencias bibliográficas}

BAER, Eugen (1988). Medical Semiotics. Lanham: University Press of America.

Deleuze, Gilles and FÉlix GuATtari (1987). A Thousand Plateaus: Capitalism and Schizophrenia II, trans B. Massumi. Minneapolis: University of Minnesota Press.

GARDNER, HowARD (1987). The Mind's New Science: A History of the Cognitive Revolution, 2nd ed. New York: Basic Books.

Lévi-Strauss, Claude (1966). The Savage Mind. Chicago: University of Chicago Press.

Merrell, Floyd (1995a). Semiosis in the Postmodern Age. West Lafayette: Purdue UP.

- (1995b). Peirce's Semiotics Now: A Primer. Toronto: Canadian Scholars' Press.

- (1996). Signs Grow: Semiosis and Life Processes. Toronto: University of Toronto Press.

OGden, C. K. and I. A. Richards (1923). The Meaning of Meaning. New York: Harcourt, Brace, and World.

Peirce, Charles SANDERs (1931-35). Collected Papers of Charles Sanders Peirce, C. Hartshorne and P. Weiss (eds.), vols. 1-6. Cambridge: Harvard UP.

Piaget, JeAn (1973). The Child and Reality. New York: Grossman.

SAVAN, DaVID (1987-88). An Introduction to C. S. Peirce's Full System of Semeiotic (Monograph Series of the Toronto Semiotic Circle 1). Toronto: Victoria College.

SCHRÖDINGER, ERWIN (1967). What is Life? and Mind and Matter. Cambridge: Cambridge UP.

TYLER, STEPHEN (1987). The Unspeakable: Discourse, Dialogue, and Rhetoric in the Postmodern World. Madison: University of Wisconsin Press.

Yourgrau, Wolfgang (1966). «Language, Spatial Concepts and Physics». In Mind, Matter, and Method, ed. P. K. Feyerabend and G. Maxwell, 496509. Minneapolis: University of Minnesota Press. 